\title{
Pengembangan Potensi Pantai Echo Beach Sebagai Daya Tarik Wisata Di Desa Canggu Kecamatan Kuta Utara
}

I Putu Aditya Adi Guna Hanuma, 1, Ida Bagus Suryawana, 2

1adityaadiguna@yahoo.com, 2idabagussuryawan@unud.ac.id

a Program Studi S1 Destinasi Pariwisata, Fakultas Pariwisata,Universitas Udayana, Jl. Dr. R. Goris, Denpasar, Bali 80232 Indonesia

\section{Abstract}

Pantai Batu mejan (Echo Beach). Beach Echo Beach is located in the village of Canggu, northern district of Kuta, Badung regency. Distance traveled to this location approximately $14 \mathrm{~km}$ from the city of Denpasar. Many foreign tourists come this beach for sunbathing, swimming and surfing while enjoying the beautiful scenery at sunset (sunset). The beach is famous as a sport surf for foreign tourists. The purpose of this study to determine the potential of Echo Beach and to determine the development strategy in Echo Beach.

The method of research is qualitative descriptive analysis with SWOT approach. The technique of collecting data is divided into four: observation, in-depth interview, documentation and literatureFor informants using purposive sampling technique. Results from this study is the tourism potential held in Turkish Echo Beach as a tourist attraction is the natural potential as sport surfing. Cultural potential that there is a sacred place (temple) and the Rejang Dance and Mask Dance. In anticipation of threats and weaknesses and increase the opportunity and power to develop the potential of Echo Beach Beach this to be sustainable, then reviewing the SWOT approach for Coastal Development Strategy in Echo Beach.

Key words: Strategy Development, Potential Tourism, Coastal Tourism

\section{PENDAHULUAN}

Bali merupakan suatu destinasi wisata yang memiliki keindahan alam yang menarik. Pulau yang terkenal dengan pariwisata di mancanegara dan nusantara, sehingga banyak dikunjungi oleh wisatawan, baik wisatawan asing maupun nusantara. Beraneka ragam keindahan alam yang mempesona. Sumber daya alam yang dilestarikan dan dijaga oleh masyarakat membawa manfaat untuk pariwisata Bali. Dalam upaya pengembangan potensi alam untuk menjadi suatu daya tarik wisata yang paling penting dibutuhkan adalah dukungan dari berbagai pihak. Pemerintah adalah memiliki wewenang untuk pembangunan pariwisata Bali dengan membuat regulasi tentang kepariwisataan.

Kabupaten Badung yang sering dikunjungi wisatawan namun belum berkembang secara maksimal adalah Pantai Batu Mejan. Pantai Batu Mejan yang dapat disebut juga dengan Pantai Echo Beach berlokasi di Desa Canggu, Kecamatan Kuta utara, Kabupaten Badung. Jarak tempuh ke lokasi ini berjarak sekitar $17 \mathrm{~km}$ dari Kota Denpasar. Kawasan Pantai Echo Beach Pantai ini bersebelah dengan Pantai Canggu sedangkan dengan garis pantainya serupa dengan pantai Kuta dan Legian.

Nama Pantai Echo Beach tersebut digunakan pada waktu berdirinya restoran yang bernama Echo Beach dan sering dipakai oleh wisatawan mancanegara agar lebih mudah diingat. Seiring berjalannya waktu guna mengembangkan potensi Pantai Echo Beach sebagai daya tarik wisata di Desa Canggu.

Berdasarkan latar belakang sebelumnya, tujuan dalam penelitian ini adalah :

1. Untuk mengetahui potensi wisata yang dimiliki di Pantai Echo Beach Desa Canggu.

2. Untuk mengetahui strategi pengembangan di Pantai Echo Beach sebagai daya tarik wisata di Desa Canggu.

\section{Tinjauan Pustaka}

\subsection{Komponen Pariwisata}

Inskeep (1991:38), menjelaskan berbagai macam komponen-komponen wisata yang ada merupakan komponen dari dasar wisata. Menurut Inskeep menjelaskan tentang komponen-komponen tersebut saling berinteraksi satu dengan yang lainnya. Dijelaskan bahwa komponen-komponen wisata tersebut dapat dikelompokkan sebagai berikut Inskeep (1991:38) :

1. Komponen atraksi dan kegiatan-kegiatan wisata.

2. Komponen aksesibilitas.

3. Komponen fasilitas dan pelayanan wisata.

4. Komponen elemen kelembagaan.

\subsection{Konsep Potensi Wisata}

Penelitian ini memakai konsep potensi wisata untuk dapat mengkaji potensi-potensi wisata yang dimiliki di Pantai Echo Beach. 
Menurut Mariotti dalam Yoeti (1983: 160-162) Pengertian potensi-potensi wisata adalah segala sesuatu yang terdapat di daerah tujuan wisata, dan merupakan daya tarik agar wisatawan mau datang berkunjung ke destinasi tersebut. Potensi-potensi wisata dibagi menjadi tiga macam, yaitu: potensi kebudayaan, potensi alam dan potensi manusia.

1. Potensi Kebudayaan

2. Potensi Alam

3. Potensi Manusia

\subsection{Konsep Daya Tarik Wisata}

Penelitian ini memakai konsep potensi wisata untuk dapat mengkaji daya tarik wisata di Pantai Echo Beach. menurut A. Yoeti , 1985 menjelaskan bahwa daya tarik wisata atau "tourist attraction", adalah istilah yang digunakan segala sesuatu yang menjadi daya tarik bagi wisatawan untuk mengunjungi suatu daya tarik wisata tertentu.

Menurut Nyoman S. Pendit, 1994 mendefinisikan destinasi wisata sebagai salah satu yang menarik dan bernilai untuk dikunjungi dan dilihat. Daya Tarik Wisata itu harus dikelola sedemikian rupa agar keberlansungan dan kesinambungannya terjamin. Adapun daya tarik wisata sebagai berikut :

1. Daya tarik wisata alam adalah daya tarik wisata ciptaan Tuhan Yang Maha Esa yang berwujud

2. Daya tarik wisata hasil karya

Daya tarik wisata yang diciptakan manusia yang berupa museum, peninggalan bersejarah, seni budaya dan tempat hiburan.

3. Daya tarik wisata ciptaan buatan

\subsection{Konsep Pengembangan Pariwisata}

Menurut

A.Yoeti,

(1983:56)

Pengembangan pariwisata adalah segala suatu usaha yang dilakukan secara terstruktur dan berencana untuk memperbaiki daya wisata yang sedang di pasarkan ataupun dipromosikan.

\section{METODE PENELITIAN}

\subsection{Lokasi Penelitian}

Penelitian tersebut mengambil lokasi di Desa Canggu, Kecamatan Kuta Utara Badung Bali. Pantai Batu Mejan yang dapat dikatakan juga sebagai pantai Echo Beach Obyek penelitian ini adalah sumber daya alam yang bisa dijadikan sebagai pengembangan potensi wisata di Pantai Echo Beach.

\subsection{Jenis dan Sumber Data}

Penelitian tersebut menggunakan metode penelitian kualitatif. Data Kualitatif adalah data yang bersifat uraian dan bukan bernilai numerik atau bukan angka (kusmayadi, 2000).

Sumber data yang dipakai dalam penelitian tersebut adalah

1. Data primer

Data yang didapat dan dicatat dengan secara langsung oleh peneliti di objek penelitian. penelitian dengan menentukan kriteria-kriteria yang telah ditentukan yaitu: pengelola Pantai Echo Beach dan masyarakat lokal Desa Canggu.

2. Data sekunder

Data tersebut diperoleh pada orang lain atau instansi yang terkait dalam hal publikasi, (Kusmayadi, 2000). Data tersebut berupa sejarah dari Pantai Echo Beach dan profil Desa Canggu.

\subsection{Teknik Pengumpulan Data}

Untuk menentukan teknik pengumpulan data penelitian ini melakukan observasi, wawancara mendalam melalui metode (purposive sampling), studi pustaka dan dokumentasi.

Dalam metode teknik pengumpulan data dengan teknik purposive sampling yang didasarkan pada ciri dan sifat pada sumber data yang dilihat mempunyai kemampuan dan keahlian yang mampu memberikan informasi yang berkaitan dengan permasalahan dalam penelitian tersebut. Dalam hal ini peneliti dapat menentukan dan memilih subyek penelitian tersebut sebagai informan kunci.

Adapun subyek dari penelitian ini maka yang menjadi narasumber adalah Kepala pengelola Pantai Echo Beach dan masyarakat yang tinggal dekat dengan Pantai Echo Beach.

\subsection{Teknik Analisis Data}

Teknik analisis data yang dipergunakan dalam penelitian tersebut adalah

1. Teknik analisis deskriptif kualitatif yaitu analisis yang dilakukan dengan cara mendeskripsikan dan menguraikan secara detail data yang diklarifikasi dan diolah. Dalam hal ini dengan menguraikan dan 
mendeskripsikan secara detail bagaimana potensi-potensi wisata yang dimiliki di Pantai Echo Beach dan pengembangan potensi Pantai Echo Beach dengan mengkaji analisis SWOT.

2. Metode SWOT

Pendekatan SWOT yaitu (Strength), Kekuatan, (Weakness) Kelemahan , (Opportunities) Peluang dan (Threats) Ancaman terhadap pengembangan Pantai Echo Beach sebagai daya tarik wisata di Desa Canggu.

fungsi dari pendekatan SWOT adalah untuk mengkaji potensi yang dimiliki oleh Pantai Echo Beach dan strategi pengembangan potensi Pantai Echo Beach yaitu:

1. Kekuatan (Strength)

Kekuatan yang dimaksud adalah potensi alam yang dimiliki oleh Pantai Echo Beach baik potensi fisik maupun potensi non fisik yang mendukung pengembangan potensi Pantai Echo Beach.

2. Kelemahan (Weakness)

Kelemahan merupakan faktor-faktor yang berasal dari dalam yang menghambat atau tidak mendukung dalam proses pengembangan Pantai Echo Beach.

3. Peluang (Opportunities)

Peluang yang dimaksud merupakan hal-hal dari luar yang mendukung pengembangan Pantai Echo Beach sebagai daya tarik wisata di Desa Canggu. Jadi kondisi ini dapat Menarik wisatawan, penambahan sarana dan prasarana kepariwisataan.

4. Ancaman (Threats)

Tantangan atau ancaman dalam hal ini adalah Adanya kecenderungan alih fungsi lahan dari fungsi pertanian produktif menjadi lahan industri pariwisata.

Disesuaikan dengan kelemahan dan kekuatan internal serta peluang dan ancaman eksternal yang dimiliki oleh Pantai Echo Beach data yang muncul. Berikut ini adalah Matrik SWOT yang menghasilkan 4 set untuk menyusun faktor-faktor yang dimiliki oleh Pantai Echo Beach.
Tabel 3.1 Matrik SWOT

\begin{tabular}{|c|c|c|}
\hline \multirow[b]{2}{*}{ EFAS } & & WEAKNESSES(w) \\
\hline & $\begin{array}{l}\text { Penentuan kekuatan di } \\
\text { dalam }\end{array}$ & $\begin{array}{l}\text { Penentuan faktor- } \\
\text { faktor kelemahan di } \\
\text { dalam }\end{array}$ \\
\hline $\begin{array}{l}\text { OPPORTUNI } \\
\text { TIES (O) }\end{array}$ & STRATEGI (SO) & STRATEGI (WO) \\
\hline $\begin{array}{l}\text { Penentuan } \\
\text { faktor- } \\
\text { faktor } \\
\text { peluang di } \\
\text { luar }\end{array}$ & $\begin{array}{lr}\text { Menciptakan strategi } \\
\text { dengan mengggunakan } \\
\text { kekuatan untuk } \\
\text { memaksimalkan } \\
\text { peluang }\end{array}$ & $\begin{array}{l}\text { Menciptakan strategi } \\
\text { yang meminimalkan } \\
\text { kelemahan untuk } \\
\text { memaksimalkan } \\
\text { peluang }\end{array}$ \\
\hline TREATHS & STRATEGI (ST) & STRATEGI (WT) \\
\hline $\begin{array}{l}\text { Menentukan } \\
\text { faktor } \\
\text { ancaman di } \\
\text { luar }\end{array}$ & $\begin{array}{l}\text { Menciptakan strategi } \\
\text { dengan menggunakan } \\
\text { kekuatan untuk } \\
\text { mengetahui ancaman }\end{array}$ & $\begin{array}{l}\text { Menciptakan Strategi } \\
\text { yang meminimalkan } \\
\text { kelemahan dan } \\
\text { mengatasi ancaman }\end{array}$ \\
\hline
\end{tabular}

Sumber : Analisis SWOT Teknik Membelah Kasus (Rangkuti,2002:31)

\section{HASIL DAN PEMBAHASAN \\ 4.1 Gambaran wilayah Canggu}

Desa Canggu yang berada di wilayah Kabupaten Badung Kecamatan Kuta Utara dengan Luasnya adalah 371,50 Ha. Pada tahun 2014 penduduknya berjumlah 6164 jiwa. Desa canggu memiliki beberapa pantai yaitu : Pantai Nelayan, Pantai Batu Bolong dan terakhir Pantai Batu Mejan atau dapat Disebut Juga sebagai Pantai Echo Beach. Terdapat juga Pura Batu Bolong dan Pura Batu Mejan. Desa Canggu terdapat 8 Banjar adat. (Buku Potensi Desa Canggu 2014)

\subsection{Potensi Pantai Echo Beach}

Dalam penelitian ini Pantai Echo Beach memiliki potensi wisata yang dapat dikembangkan menjadi suatu daya tarik wisata di bagi menjadi 3 macam yaitu : Potensi Alam, Potensi Kebudayaan, Potensi Manusia.

1. Potensi Alam

Pantai Echo Beach memiliki potensi alam yang bagus untuk dikembangkan sebagai sport surfing bagi wisatawan ini adalah suatu tantangan olahraga air. pada bulan juli hingga agustus adalah waktu yang bagus untuk surfing, karena pada bulan tersebut ombaknya bagus untuk melakukan surfing. selain itu keindahan bebatuan karang yang terdapat di pinggir pantai. Wisatawan yang mengunjungi ke pantai melakukan kegiatan wisata seperti : surfing, 
photography di bebatuan karang dan ada juga yang sekedar berjemur di pantai.

2. Potensi Kebudayaan

Di area pantai terdapat sebuah tempat suci (pura) yang dinamakan Pura Batu Mejan. Kegiatan yang dilakukan oleh masyarakat Desa Canggu pada Hari raya Umat Hindu Tujuan Dari adanya Upacara persembahyangan Caru Merta Gangga adalah untuk hasil yang baik bagi pertanian dan panen yang melimpah. Terdapat juga batu berlobang bersemayamnya Linggih Angin Puting Beliung dan Ratu Gede Balengbong. Sejarah dari Pura Batu Mejan adalah perjalanan seorang Ida Pedanda Sakti Wau Rauh ke Pura Batu Mejan.

3. Potensi Manusia

Masyarakat Desa Canggu budaya setiap upacara yang dilaksanakan di Pura Batu Mejan berkontribusi dalam membantu jalannya upacara seperti tari-tarian dan menjadi ciri khas dari desa canggu adalah Tari Rejang dan Tari Topeng.

\subsection{Analisis matrik SWOT Pengembangan Pantai Echo Beach Sebagai Daya Tarik Wisata di Desa Canggu}

1. Strengths (s)

- Pantai Echo Beach yang memiliki keindahan bebatuan karang port surfing.

- Budaya dan sebagai tempat yang dimiliki di Desa canggu masih dilestarikan oleh masyarakat Desa canggu seperti : kesenian menari.

2. Weaknesses (w)

- Penataan objek yang belum optimal.

- Terjadinya peralihan fungsi lahan

- Minimnya fasilitas umum yang tersedia di area pantai seperti : Toilet, Tempat Parkir, Tempat sampah.

- Kebersihan belum terjaga.

3. OPPORTUNITIES (O)

- Pantai Echo Beach lebih dikenal oleh wisatawan mancanegara sebagai sport surfing.

- Terbukanya lapangan pekerjaan.

- Munculnya fasilitas penunjang kepariwisataan seperti : akomodasi dan restoran.

4. TREATHS (T)

- Kurangnya promosi pariwisata

- Pengaruh akulturasi budaya barat yang tidak sesuai dengan budaya lokal.
- Pembangunan yang tidak terkontrol akan dapat merusak lingkungan.

5. STRATEGI (SO)

- Melaukan promosi dengan bekerja sama melalui travel agent untuk menarik wisatawan yang menyukai sport surfing.

- Melakukan pemberdayaan kepada masyarakat lokal pentingnya pariwisata dan merekrut masyarakat lokal sebagai tenaga kerja di industri pariwisata di desa Canggu.

6. STRATEGI (WO)

- Menata kembali area pantai dimulai dari zona bibir pantai, fasilitas umum dan fasilitas penunjang kepariwisataan.

- Bekerja sama dengan pemerintah untuk membersihkan area pantai dengan rutin dan diberikan fasilitas tempat sampah di pantai.

7. STRATEGI (ST)

- Pengelola pantai membuat sangsi bagi pihak swasta yang membangun industri di lahan hijau.

- Masyarakat lokal mampu mecermati baik dengan masuknya budaya barat ke budaya lokal.

8. STRATEGI ( WT)

- Segera dilakukan penataan objek sesuai dengan tata ruang yang ada.

- Melakukan pembinaan untuk masyarakat agar tidak mengikuti kebudayaan barat dan tetap menjaga budaya lokal.

\section{SIMPULAN DAN SARAN}

\subsection{Simpulan}

Berdasarkan hasil pembahasan diatas, maka dapat ditarik kesimpulan sebagai berikut :

Potensi wisata yang dimiliki di Pantai Echo Beach Desa canggu untuk sebagai daya tarik wisata adalah potensi alam yang bagus untuk dikembangkan sebagai sport surfing Wisatawan juga dapat berjemur sambil melihat sunset pada sore hari. Potensi Kebudayaan yang dimiliki oleh Pantai Echo Beach Di area pantai terdapat sebuah tempat suci (pura) yang

Setiap upacara agama yang dilaksanakan di Pura Batu Mejan berkontribusi dalam membantu jalannya upacara seperti tari-tarian dan menjadi ciri khas dari desa canggu adalah Tari Rejang dan Tari Topeng. Untuk mengantisipasi dari ancaman dan kelemahan dan meningkatkan peluang dan kekuatan untuk pengembangan potensi Pantai Echo Beach ini agar menjadi keberlanjutan, maka 
Strategi Pengembangan Pantai Echo Beach yang dilakukan adalah sebagai berikut :

1. Strategi SO

Melakukan promosi dengan bekerja sama melalui travel agent, pihak swasta. Melakukan pemberdayaan kepada masyarakat lokal Desa Canggu terhadap pentingnya pariwisata dan perekrutan tenaga kerja lokal untuk ditempatkan di industri pariwisata yang terdapat di dekat pantai tersebut.

2. Strategi WO

Menata kembali area pantai dimulai dari zona bibir pantai, fasilitas umum, dan fasilitas penunjang kepariwisataan.

3. Strategi ST

Pihak pengelola pantai bersitegas membuat aturan atau sangsi tertulis bagi pihak swasta yang membangun hotel atau restoran di lahan hijau.

4. Strategi WT

Melakukan pembinaan untuk masyarakat lokal Desa Canggu

\subsection{Saran}

\section{DAFTAR PUSTAKA}

Inskeep,E.1991,Tourism planning.En Integrated and Suitanable Devepelopment

Approach .

Kusmayadi \& Endar Sugiarto. 2000, Metodologi Penelitian dalam Bidang Kepariwisataan.Jakarta: PT.Gramedia Pustaka Utama

Pendit, Nyoman S. 1994. Ilmu Pariwisata. Jakarta: PT Pradnya Paramita.

Rangkuti, Freddy. 2002, Analisis SWOT Teknik Membelah Kasus. Jakarta: Gramesdia Pustaka

Sukardi. Nyoman. 1998. Pengantar Pariwisata.STP Nusa Dua Bali. George R. Terry. 2000, Prinsip-Prinsip Manajemen. (Edisi Bahasa Indonesia). PT. Bumi Askara : Bandung

Undang-undang no 10 Tahun 2009 tentang kepariwisataan. Yoeti, Oka A. 1985. Pengantar Ilmu Pariwisata. Bandung: Angkasa.

Yoeti, Oka A. 1983.Perencanaan dan Pengembangan Pariwisata. Jakarta: PT.PradnyaParamita.

Jurnal Perhotelan dan Pariwisata, Januari - Juni 2014, Vol.1 No.4 hal.11

Buku Profil Desa Canggu 2014 http://badungtourism.com/potensi
Adapun beberapan saran yang dapat diberikan adalah sebagai berikut:

1. Pihak pengelola Pantai Echo Beach melakukan promosi baik melalui offline dan online dan bekerja sama dengan travel agent untuk mendatangkan wisatawan. membangun fasilitas umum untuk wisatawan seperti : toilet/kamar mandi, tempat sampah dan lahan parkir yang diperluas.

2. Pemerintah yang sebagai fasilitator dan regulator dibutuhkan untuk membuat aturan tegas dengan sangsi bagi investor yang membangun atau mendirikan hotel.restoran, dan villa di lahan hijau. Pemerintah juga memberikan dukungan sosial bagi masyarakat lokal guna pengembangan Pantai Echo Beach.

3. Masyarakat Lokal khususnya Desa Canggu lebih melihat peluang dan mencermati lapangan pekerjaan yang terdapat di industri pariwisata. Melestarikan budaya kesenian seperti : tari rejang dan tari topeng tersebut. Memilah masuknya budaya asing mana yang baik dan tidak baik.

4. Untuk penelitian selanjutnya perlu adanya kajian yang lebih mendalam tentang pengembangan potensi Pantai Echo Beach tersebut.

Batu_Mejan_Beach_(Echo_Beach).html?lang=id Diakses tanggal 5 April 2015 